\title{
Mètodes naturalistes de la sociologia de la creativitat: contra el reduccionisme
}

\author{
Dafne Muntanyola-Saura \\ UNIVERSITAT AUTÒNOMA DE BARCELONA \\ dafne.muntanyolaßauab.cat \\ ORCID: 0000-0002-2684-9577
}

Rebut: 28/04/2020

Acceptat: 17/03/2021

\section{RESUM}

En el context canviant dels consensos bàsics que constitueixen la cultura legítima i les definicions de creativitat, la sociologia de la cultura hi juga un paper important. Nombrosos estudis en ciències socials i cognitives ho demostren empíricament (Bourdieu, 1979; Becker, 1982; 2002; Sennett, 2012; Muntanyola-Saura, 2012; 2014; 2016). La creativitat com a forma de cognició social forma part d'un context institucional. No obstant això, la influent branca culturalista de la sociologia cognitiva (CCS) redueix la creativitat a un nivell psicològic cognitivista (Lizardo i Strand, 2010). Partim aquí de la conjectura que és possible per a la sociologia de la cultura aprofitar el paradigma naturalista de la cognició per explicar la creativitat sense caure en postures reduccionistes ni atomistes. Per tant, el cos de l'article és una revisió bibliogràfica que sense tenir la ambició de ser exhaustiva sí que ofereix una mirada completa sobre uns models pragmàtics i integrats de creativitat. Es té en compte la diversitat de propostes teòricoempíriques que existeixen, per tal d'identificar els postulats de partida dels autors que centralitzen el debat tant a nivell macro com a nivell micro. Els estudis analitzats presenten processos intersubjectius de creació i transmissió de criteris més o menys legítims de consum cultural, com ara categoritzacions, avaluacions i judicis estètics. La conclusió és que la perspectiva sociològica pot reforçar críticament la creativitat.

Paraules clau: sociologia de la cultura, legitimitat, gust, etnometodologia, Lizardo, Bourdieu.

ABSTRACT. Naturalist Methods in the Sociology of Creation: The Case Against Reductionism

The Sociology of Culture has much to say when it comes to the ever-changing general consensus on what constitutes legitimate culture and definitions of creativity. The naturalistic studies on cognition in social and cognitive sciences show this empirically (Bourdieu, 1979: Becker, 1982, 2002; Sennett, 2012; Author, 2014). Creative cognition is part of an institutional context. However, the influential culturalist branch of cognitive sociology (CCS) reduces creativity to a cognitivist psychological level (Lizardo and Strand, 2010). We start from the conjecture that the Sociology of Culture can draw on the naturalistic paradigm of cognition to explain creativity without falling into reductionist or atomist positions. The authors take the diversity of theoretical-empirical proposals into account in identifying the starting points for focusing the debate at both the macro and micro levels. The body of the article comprises a literature review which, while not exhaustive, offers a full picture of the pragmatic and integrated models of creativity. The studies analysed present inter-subjective processes of creation and the transmission of variable legitimate criteria concerning cultural consumption such as categorisations, evaluations and aesthetic judgments. The sociological perspective offers scope for strengthening critical tools for examining creativity.

Keywords: sociology of culture, legitimacy, taste, ethno-methodology, Lizardo, Bourdieu. 


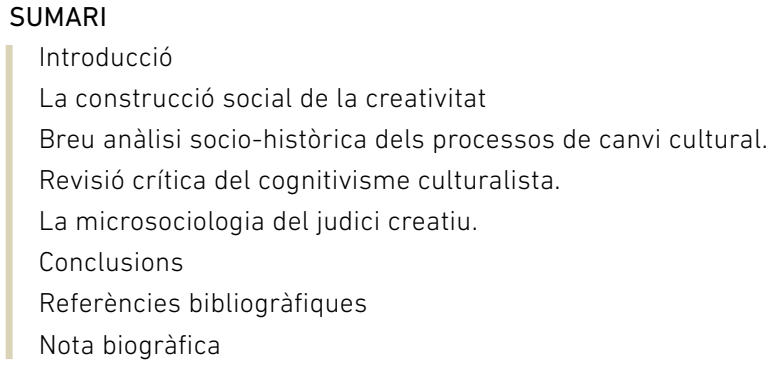

Autora per a correspondència / Corresponding author: Dafne Muntanyola-Saura. Departament de Sociologia. Edifici B, Carrer de la Fortuna. Campus de la UAB · 08193 Bellaterra. Cerdanyola del Vallès (Espanya).

Citació suggerida / Suggested citation: Muntanyola-Saura, D. (2021). Mètodes naturalistes de la sociologia de la creativitat: contra el reduccionisme. Debats. Revista de cultura, poder i societat, 135(2), 25-38. DOI: http://doi.org/10.28939/iam.debats.135-2.2

\section{INTRODUCCIÓ}

Necessitem espai per a pensar, per a debatre, per a llegir, per a crear. En el context canviant dels consensos bàsics que constitueixen la cultura legítima i les definicions de creativitat, la sociologia de la cultura hi té molt a dir. La cognició creativa no és només un producte psicològic local, sinó que forma part d'un context social. La sociologia de la cultura contempla la creativitat com un fenomen estructurat per factors com el gènere, la classe social o el marc nacional. Els estudis naturalistes sobre la cognició en ciències socials i cognitives ho demostren empíricament (Bourdieu, 1979; Becker, 1982; 2002; Sennett, 2012; Muntanyola-Saura, 2012; 2014; 2016). Emprem el terme «naturalista» en el sentit que apareix en la tradició filosòfica de considerar el coneixement de l'activitat humana i social com una realitat donada per descomptat. Aquesta és la base de la perspectiva sociològica i, més concretament, del construccionisme social ben entès. No obstant, la branca culturalista de la sociologia cognitiva (CCS) redueix la creativitat a un nivell psicològic (Lizardo i Strand, 2010). La presa de decisions, tal com la defineix la CCS, seria una activitat individual, inconscient i que segueix regles que no estan directament configurades per factors socials. Se suposa que les persones reaccionen automàticament, sense sistematització ni reflexivitat, a estímuls externs de l'entorn social. El procés de socialització i el contingut lingüístic i conceptual del pensament esdevenen secundaris.

Partim aquí de la conjectura que és possible per a les ciències socials aprofitar el paradigma naturalista de la cognició per explicar la creativitat sense caure en postures reduccionistes ni atomistes. Es tindrà en compte la diversitat de les propostes teòrico-empíriques existents, per tal d'identificar els postulats de partida dels autors que centralitzen el debat tant a nivell macro com micro. Els objectius de l'article són els següents: 1) argumentar la construcció social de la creativitat; 2) definir l'origen socio-històric de la creativitat en tres processos de canvi cultural; 3) presentar les principals escoles teòriques que en sociologia formulen una anàlisi naturalista de la creativitat; 4) recollir les aportacions que busquen comprendre a escala micro pràctiques concretes considerades com a creatives. Per tant, el cos de l'article és una revisió documental que, sense pretendre ser exhaustiva, sí que consolida una mirada completa sobre un model pragmàtic i integrat de la creativitat.

\section{LA CONSTRUCCIÓ SOCIAL DE LA CREATIVITAT}

La creativitat és una pràctica individual o col-lectiva? L'objecte d'aquest article és l'embolcall de la 
creativitat, és a dir, el context de producció de les activitats que socialment considerem com a creatives. Aquí no entrarem a discutir quin és el disseny neuronal que fa possible la creativitat, la qual cosa és un objecte en sí mateixa: els exemples de best-sellers de neurocientífics que aborden aquest tema serien Dennett (1995), Damasio (1999), Ramachandran i Blackeslee (1999), i Gallese, Keysers i Rizzolatti (2004). Tampoc ens esplaiarem en explicar quines capacitats psicològiques, com l'atenció o la percepció, faciliten $\mathrm{o}$, al revés, dificulten allò que en anglès s'anomena aha moment, és a dir, quan se'ns encén la bombeta i tenim «la» idea. D'aquesta manera, deconstruïm tres idees sobre la creativitat: la universalitat d'allò considerat com a creativitat, l'ideal romàntic de l'individu creatiu i la reifficació de la pràctica creativa.

D'entrada, s'està definint la creativitat com una pràctica $i$, per tant, com una activitat que té lloc en el món social, lluny de termes com «instint», «motivació» $\mathrm{O}$ «inspiració», tots ells processos psicològics. Des de la sociologia, emprem el terme «legitimitat» per parlar d'aquelles activitats socials acceptades i transmeses per les institucions socials dominants i etiquetades per tant com a normals i desitjables (Berger i Luckmann, 1988). La pràctica creativa és patrimoni dels professionals tant de mons artístics com científics. Que la creativitat no és una pràctica exclusiva d'aquests professionals ho tenim clar: Merton (1945) ja posa de manifest que la creativitat científica no és només un producte intencional, sinó que també hi entra l'atzar, la serendipitat. I la creativitat no és un bé escàs, sinó que és una propietat inherent a la pràctica social en qualsevol entorn institucional, com diu Becker (2017). En termes de Joas (1996), no existeix creativitat sense la intersubjectivitat de l'acció organitzada socialment. Però també és cert que les pràctiques professionals socialment legitimades com a creatives són unes i no unes altres. I és aquí on podem explorar, des de la sociologia, quines són les convencions que defineixen allò que és art, i allò que no ho és, com també afirma Becker (1982). En vocabulari bourdieusià, no tota pràctica creativa és susceptible de ser considerada un capital cultural.
També podríem parlar de termes associats com el d'innovació o emprenedoria, que vinculen necessàriament la creativitat amb la tecnologia d'una banda, i amb l'empresa privada de l'altra. Per exemple, si busqueu «creativitat i innovació» a Google, us sortiran dues entrades sobre creativitat i educació escolar; i la tercera serà del postgrau d'Emprenedoria, Creativitat i Processos d'Innovació Interdisciplinaris de la Facultat d'Economia i d'Empresa de la UB. El curs es presenta de la manera següent:

La competitivitat passa sovint per la capacitat d'idear i gestionar projectes interdisciplinaris que generin per si mateixos nous mercats i aportin una diferenciació clau per tal que els projectes es consolidin. Aquest programa de postgrau està dissenyat per aprofundir en les connexions entre creativitat i innovació. L'objectiu general és assolir els coneixements, habilitats i les competències bàsiques per desenvolupar projectes innovadors mitjançant el treball col-laboratiu i la utilització d'eines creatives.

El nom de les coses, el procés d'etiquetatge (labeling) que tan bé argumenta Becker (1982), ens permet fer aquest exercici de deconstrucció semàntica. Per tant, la creativitat aquí és una competència adquirida en un entorn d'educació formal vinculat al mercat capitalista amb l'objectiu d'incrementar la competitivitat empresarial. Es tracta d'una concepció legitimada pel currículum universitari que respon a una visió molt allunyada d'altres concepcions, com l'artística, per exemple. Per tant, la primera idea clau és que la polisèmia de la creativitat no deixa de ser el producte dels processos de construcció de legitimitat social.

La segona idea és que l'imaginari social associa la creativitat a la torre d'ivori del geni romàntic, l'artista que es tanca a l'estudi i treballa malgrat els altres i no gràcies a ells. Aquest va ser el gran mite de la modernitat, que Paul Feyerabend (1987) ataca de ple i que es vincula amb el geni romàntic tancat a la torre d'ivori propi del segle xIx i que encara ara perdura. El filòsof anarquista fou autor del famós Contra el Mètode (Feyerabend, 1975) que mostrava la ciència com a institució opaca i indi- 
vidualista. Anys després, ho feia en «Creativity, a dangerous myth» (1987), un article menys conegut que condensa una visió alternativa a la creativitat moderna i explica com la creativitat no es dona en un buit social, dins del cervell d'un artista o d'una científica. Segons Feyerabend, la creativitat, com a pràctica, es dona en unes determinades condicions materials i històriques, amb un component atzarós de caràcter processual i acumulatiu. Feyerabend comenta el cas dels artesans del Renaixament, que treballaven en una determinada estructura política, a les ciutats toscanes, finançats per un mecenes, i que basaven el seu reconeixement social en la seva expertesa per dominar un disseny, uns materials i unes eines. Quin podria ser un exemple actual? Les institucions d'educació formal, com l'escola o la universitat, haurien de ser, segons aquesta perspectiva contextual, institucions que afavorissin la creativitat dels que hi treballen o hi estudien. El pla «Escola Nova 21» de renovació pedagògica i el creixement d'escoles lliures són exemples de la presa de consciència per part de l'opinió pública de la importància del context, de la formació dels mestres, de la metodologia pedagògica, però també del tipus de recursos materials de què gaudeix una escola.

La tercera idea és prendre consciència que no podem congelar la creativitat i donar-li un contingut unívoc, sinó que la pràctica creativa és sempre relativa a una societat, a un moment, a un temps. No podem identificar la capacitat de crear, de ser lliures, d'imaginar, de tenir noves idees, amb un determinat currículum, un estil arquitectònic o un determinat accent. Feyerabend no nega l'existència d'un gust o un judici estètic, sinó que posa de relleu l'error escolàstic, o reïficació, present tant en el món acadèmic com en la vida quotidiana, que col-loca una activitat que pertany a la producció cultural d'un moment històric al lloc d'un principi general. La reïficació afecta altres conceptes centrals en les ciències socials, com el de cultura. En aquest sentit, Mario Bunge distingeix entre una concepció empírica i una construcció idealitzada d'aquestes pràctiques culturals:
La cultura d'una societat avançada està composta d'un gran nombre de subsistemes, com els col-lectius professionals, la indústria del cinema, les esglésies i les editorials. Aquesta caracterització (sociològica) es contraposa amb la concepció idealista de la cultura com una col-lecció d'objectes sense cos, com la moral, l'art o la religió considerats en si mateixos, sense tenir en compte la gent que produeix o consumeix articles i serveis morals, artístics o religiosos. (Bunge, 2018)

En efecte, les maneres de fer feina, de presentar-se com a artista, així com les fonts de legitimitat d'aquestes maneres de treballar, han canviat històricament, tant com les formes de relació familiar i de producció capitalista. El mite de la creativitat individual comença amb el dualisme cartesià entre cos i ment, matèria i esperit, pensament i sensació, raó i intuïció. Com afirma Bruno Latour (1986), un home nou no va emergir de cop en algun moment del segle xvi. La dimensió arbitrària es fa evident en la comparació històrica d'entorns professionals. Gràcies a les aportacions del sociòleg francès Pierre Bourdieu (1979; $1984 ; 1994)$, podem veure en quina mesura les eines de legitimació per a la decisió artística es construeixen professionalment. Un artista contemporani aprèn a justificar la qualitat de la seva obra quan la sap vendre a un possible comprador, com una galeria, i per tal de promocionar-se, ha d'emprar els termes que estan acceptats i que comparteixen els que formen part d'aquest camp. Per tant, podem dir que existeix una manera de fer que s'aprèn treballant en el món de l'art, i que adquireix la forma d'un «habitus», una manera de mirar, de pensar i de dir. Per exemple, en la quotidianitat existeix l'habitus de comprador habitual de llibres: hi ha una manera de caminar per la llibreria, de tocar els llibres, de mirar-los, de sospesar-los, una direccionalitat que indica una intenció de buscar o de trobar un llibre determinat, una manera de parlar amb la llibretera, etc. Per tant, la creativitat és una activitat que pren forma al llarg del temps i de l'espai, de manera canviant, seguint un habitus definit socialment. 


\section{BREU ANÀLISI SOCIO-HISTÒRICA DELS PROCESSOS DE CANVI CULTURAL}

L'aproximació sociològica més consolidada en la cultura popular occidental és la crítica a la «cultura de masses». Tot i que els conceptes de «societat de masses» $\mathrm{i}$ «cultura de masses» venen de més lluny, no prenen la importància capital que tenen per a l'anàlisi de la cultura i la societat fins als anys trenta del segle passat, i no es consoliden fins passada la Segona Guerra Mundial. Intel-lectuals de l'elit cultural nord-americana i europea reprenen amb força la crítica, iniciada al segle XIX, que es basa en la percepció d'un món modern que ha diluït les institucions socials secundàries entre la massa de ciutadans individuals i les estructures centralitzades del poder. Membres destacats de l'Escola de Frankfurt creuen que l'individu, en la «societat de masses», es veu alienat i aillat, i és llavors susceptible de ser manipulat políticament pel líder autoritari de torn, quedant així mateix culturalment anul-lat per la maquinària de la «indústria cultural» (Adorno i Horkheimer, 1972; 1994; Ariño i Llopis, 2017). La dicotomia entre l'alta cultura i la cultura popular resulta en el principi de jerarquització social i en la voluntat de distinció. Aquest debat es troba actualment en un moment clau per tres processos de transformació social que expliquem a continuació: la mercantilització, la democratització i la individualització.

1) La mercantilització de les indústries culturals en els 50 i 60 marquen el col-lapse del primer projecte de democratització cultural, que volia garantir un accés a la Cultura en majúscules per part del gruix de la població, el qual «s'elevaria» culturalment per mitjà de polítiques públiques. Aquesta idea, que es va concretar a nivell pràctic en garantir l'escolarització universal i facilitar l'accés a l'alta cultura, encara perviu en cercles culturals i artístics, per la qual cosa legitima una jerarquia cultural. El públic es fa heterogeni i el mercat s'estratifica. Els productes culturals com el cinema apel-len a diferents públics i apareix la idea dels nínxols de mercat i del màrqueting dirigit a sectors de població definits en termes de classe, estatus, capital cultural, gènere o raça.
Així, l'acte de consum cultural passa a ser l'acte més destacat d'integració social. Lipovetsky (2007) defineix els valors que comencen a consolidar-se en aquest moment com propis de la hipermodernitat, en què consumir és l'acte que defineix la identitat d'un ciutadà responsable. Un es defineix pel que compra i consumeix en cultura perquè té accés a un mercat que abans estava tancat per a la majoria. Fent un pas més, el mateix autor afirma conjuntament amb Serroy (2015) que actualment els models de consum han construït una dualitat ètica i estètica: d'una banda, l'acceleració del consum i de la vida, per la mediació de la tecnologia; i de l'altra, la crida al decreixement en tots els sentits: econòmic, cultural i emocional.

2) El procés de democratització en els seixanta i setanta posa de manifest el caràcter limitat de les polítiques d'accés als recursos culturals. La consolidació del procés de mercantilització no va implicar la desaparició de les jerarquies socials ni una democratització real. Apareixen les veus crítiques amb l'abast real de l'accés a la cultura. Així, a finals dels seixanta, la modernitat entra en crisi. Bourdieu (1979), entre d'altres, va evidenciar el solapament entre les jerarquies culturals i les socials, el sexe i l'edat. Aquesta mirada crítica posa en qüestió la consideració del gust de les classes altes com l'únic gust legítim i vincula les diferents pautes de consum cultural a la posició dels individus en l'estructura social. L'aportació de Bourdieu és una garrotada a l'ideal democràtic de cultura predominant fins llavors. Identifica els límits de les polítiques de culturalització de la població, que tenen un efecte molt més limitat del que s'havia imaginat.

Els autors del materialisme cultural britànic (Williams, 1958; Eagleton, 2000) critiquen el neutralisme liberal i afirmen que la cultura és sobretot una manera normativa d'imaginar la societat. La mirada del materialisme cultural, a més, va posar en relleu que la cultura és una activitat material abans de ser un atribut intel- 
lectual, una manera de donar sentit al món i al lloc que ocupem en ell abans que un fi en si mateix. No hi ha masses sinó discursos, perquè les formes culturals creixen, es transformen i es diversifiquen. El pessimisme d'Adorno i Horkheimer (1972) contrasta amb el posicionament més optimista dels emergents estudis culturals (Hall i Jefferson, 1975; Stuart Hall, 2007). I és que segons el materialisme cultural, la creativitat existeix i funciona materialment $i$ simbòlicament com a part de processos d'aprenentatge, de coneixement i d'estatus.

3) La progressiva individualització de les pràctiques culturals porta a una explosió d'estils de vida i d'activitats artístiques. Aquest procés de canvi de les formes de coneixement, així com les formes d'interacció i d'estar junts, ja va començar amb l'hedonisme dels seixanta. D'aquí han sorgit reflexions entorn de les conseqüències culturals de la globalització en la relació entre poder, informació i coneixement, la hibridació cultural (Regev, 2013) o l'explosió de l'expressió del gust a les xarxes socials en termes identitaris. En el camp de l'activisme, han aparegut propostes que defensen formes d'entendre la democràcia cultural mitjançant el procomú o el coneixement obert i també crítiques a la deriva ingènua que pot adoptar el «ciberfetitxisme» d'internet (Rendueles, 2013). Efectivament, els canvis en l'accés al coneixement facilitats per la tecnologia no són suficients per fer desaparèixer els condicionants socials de l'elitisme cultural: calen modificacions de les condicions socials de producció de coneixement, canvis institucionals per no reproduir la bretxa digital tant en l'accés com en l'ús, com es planteja en el debat acadèmic sobre l'alfabetització digital.

\section{REVISIÓ CRÍTICA DEL COGNITIVISME CULTURALISTA}

Localitzem en aquesta secció els paradigmes teòrics del cognitivisme culturalista, que considerem crucials per entendre els debats actuals entorn de la legitimitat de les pràctiques creatives. En efecte, la creativitat es troba en el punt de tensió entre la reproducció de la jerarquia de capitals culturals i la individualització dels gustos. Com valora Natalie Heinich (Moulin, 1999), escapar de l'autoritarisme i del populisme passa per renunciar a l'universalisme de la producció cultural i artística. És a dir, cal renunciar a l'ideal burgès de l'art per l'art. Aquest punt ha dut, ja des dels 70, a estudiar grups que no consumeixen cultura legítima, anomenats iconoclastes, no-públics (Jacobi i Luckerhoff, 2012) o inactius (López-Sintas, Cebollada, Filimon i Gharhaman, 2014). Així, Vandenberg et al. (2018) analitzen les pràctiques culturalment «il-legítimes» del camp de la música popular de Rotterdam a partir de la teoria del camp de Bourdieu i del model de processament dual de Lizardo i Strand (2010). L'estudi té l'objectiu de comprovar si la dinàmica de distinció del camp té lloc a partir de les orientacions musicals verbalitzades en l'enquesta, o bé, en paraules de les autores, a partir de «disposicions implícites més habituals».

Deixant de banda el caràcter descriptiu de la proposta, aquest tipus d'investigacions reprodueixen un cognitivisme confús. Les opinions recollides per l'enquesta administrada a individus de cultura «il.legítima» es desvinculen dels mecanismes institucionals de naturalesa relacional que precisament defineixen el seu valor com a pràctica cultural. S'atomitza el mecanisme de la distinció i de la reproducció de Bourdieu i s'ignoren les condicions socials dels processos de legitimació. La definició de legitimitat i il-legitimitat, que són el producte relacional de les condicions del camp de Bourdieu, passa a reïficar-se en aquest estudi. No es qüestionen les categories ni etiquetes d'adscripció social, perquè el focus d'anàlisi deixa de ser sociològic per passar a ser psicològic i substancialista. Una de les conseqüències d'una visió rígida de la legitimitat cultural on un model de processament dual és reproduir un paradigma reduccionista. Sota una aparent interdisciplinarietat, la branca culturalista de la sociologia cognitiva a la qual pertanyen aquests autors analitza la creativitat com un producte psicològic. Aquesta escola influent en els estudis sobre creativitat es localitza al pol reduccionista de l'eix reduccionisme/relacionisme, amb 
Becker, Bourdieu i els altres autors de la perspectiva sociològica naturalista a l'altre extrem.

Lizardo (a Brekhus, 2015) considera que el concepte d'habitus de Bourdieu és un concepte psicològic. Atribueix a Bourdieu la idea que la cultura és inconsistent, fragmentada en usos diferents i vinculada amb l'habitus de naturalesa subconscient. Afirmar que el coneixement quotidià és un procés ni lingüístic ni simbòlic, desvinculat del procés de socialització, és un doble error. Podem parlar de l'existència de mecanismes biològics, com el de la intencionalitat (Searle, 2004), la reflexivitat de segon ordre (Premack, 2004) i la projecció conceptual (Kirsh, 2009), que són condicions de possibilitat de l'habitus. Però la versió de la socialització de Lizardo (a Brekhus, 2015) és una versió «lleugera» en què els actors «només tenen un conjunt d'habilitats lliurement estructurades, heurístiques, rutines i hàbits superficials que els ajuden a navegar (i seleccionar) les accions estratègiques més adequades dins d'una estructura institucional externalitzada que assumeix la menor "sistematicitat" possible a nivell de l'actor, amb la major part de la sistematicitat projectada a l'entorn extern» (Lizardo, 2010: 208). Deixant de banda que és una frase que amb prou feines s'entén, el terme «sistematicitat» resulta ser purament descriptiu, ja que no queda clar amb relació a quin nivell d'anàlisi s'està parlant. El raonament aquí és cognitivista, ja que cau en una fal-làcia escolàstica, com diria Bourdieu (1994). Quina és aquesta fal-làcia? La de comprendre els processos cognitius no en el seu context cultural més o menys complex i històricament variable, sinó com el resultat psicològic de seguir una sèrie de normes com les dels hàbits i rutines esmentats a la cita de més amunt. Atès que, com Lizardo explica més endavant en el mateix article, aquest rule following no és lingüístic, es tracta d'un procés basat en estats mentals inconscients. Tanmateix -i aquí és on clàssics de la filosofia americana com John Searle (2004) i Hubert Dreyfus (1996) formulen una crítica brillant al cognitivisme-, tot estat mental inconscient, seguint el principi connectivista que ja apareix a l'empirisme de Hume, hauria d'aflorar la consciència en algun moment: i això aquí no passa. Per tant, aquest conjunt de regles heurístiques, psicològiques, individuals i mentals, que segons Lizardo són el nucli de la nostra cultura i cognició, simplement no existeixen.

Els punts de connexió que Lizardo (2004) estableix entre Bourdieu i Piaget són rellevants i constitueixen una contribució real a la seva tasca heurística de l'obra bourdieusiana. No obstant, en el mateix article, Lizardo (2004: 395) afirma que l'habitus és un principi abstracte, sense especificitat contextual, una «matriu transposable». Es tracta d'un llenguatge que recorda als principis de programació de la GOFAI (Good Old Fashioned Artificial Intelligence), és a dir, dels models clàssics d'intel-ligència artificial més conductista. Dit d'una altra manera, el cognitivisme de Lizardo estableix una bretxa entre el procés cognitiu neuronal i el psicològic, i aquest gap no hi és. En paraules de Searle (2004), les neurones (les mirall i les altres) causen estats intencionals. I és gràcies al mecanisme cognitiu de la intencionalitat que ens orientem a l'acció i als judicis creatius. El procés de socialització, per tant, es troba en aquesta interacció entre el nivell neuronal i l'entorn social, i el psicològic passa a ser un fantasma irrellevant. Es tracta d'un debat que ja està resolt des de la ciència cognitiva i que sembla que Lizardo no coneix. Aquest error es tradueix en una interpretació superficial del procés de socialització i de transmissió cultural. Brekhus (2015: 18) diu que Lizardo considera que les instruccions directes i la socialització no són necessàries perquè les pràctiques poden ser transmeses i recollides inconscientment per mitjà del mirall dels altres.

Lizardo resumeix en la mateixa pàgina l'aportació de Bourdieu al camp interdisciplinari entre neurociència, ciència cognitiva i sociologia cultural: «Aquests acadèmics emfatitzen els hàbits corporals en les respostes en gran mesura subconscients a l'entorn, en lloc de considerar la socialització i el llenguatge com les formes primàries per les quals la cultura s'internalitza» (Lizardo, 2004: 295). Cau en el reduccionisme de localitzar aquest procés en la interacció de les neurones amb estats mentals psicològics, quan de fet es tracta d'una relació entre l'aparell neuronal i els processos d'interacció social. Per contra, Berger 
i Luckmann (1988) dediquen més de 30 pàgines de La construcció social de la realitat a comentar passatges d'Alfred Schütz, fenomenòleg social de la New School absent de l'argumentació de Lizardo. Schütz defineix de manera concisa aquest procés de coneixement pràctic, fragmentat i de recepta que fonamenta tota interacció cognitiva. Berger i Luckmann afirmen que «Schütz es va preocupar sobretot per analitzar l'estructura del món del sentit comú de la vida quotidiana» (1988: 31-32). I una mica més avall el citen directament: «El coneixement està socialment distribuït, i el mecanisme d'aquesta distribució pot ser l'objecte d'estudi d'una disciplina sociològica».

En definitiva, els estudis sobre gustos «il-legítims», que segueixen el cognitivisme de Lizardo, no qüestionen la definició dels ítems de pràctiques culturals recollits a les enquestes com a indicadors de pràctiques culturals. Aquesta perspectiva en deixa de banda d'altres reflexives i relacionals com les ja citades. La perspectiva de Bourdieu (1984: 47), en les seves pròpies paraules, és relacional i s'oposa al reduccionisme estret i a l'atomisme:

En primer lloc, cal trencar amb la tendència de pensar el món social de forma substancialista. La noció d'espai conté, per sí mateixa, el principi d'una aprehensió relacional del món social: afirma que tota la «realitat» designant resideix en l'exterioritat mútua dels elements que la componen. Els éssers aparents, directament visibles, tant si es tracta d'individus o de grups, existeixen i subsisteixen en i per la diferència, és a dir, en tant que ocupen posicions relatives en un espai de relacions que, encara que invisible i sempre difícil de manifestar empíricament, és la realitat més real, el principi real dels comportaments dels individus i dels grups.

Altres autors reconeguts en el camp de la sociologia de la cultura, com DiMaggio (1987), plantegen un compendi de possibilitats d'interpretació de les classificacions artístiques sense caure en allò donat per descomptat. Més recentment, Johnson, Dowd i Ridgeway (2006) reivindiquen la necessitat de realitzar una anàlisi sistemàtica de la deslegitimació com a procés social. I Lamont (2010), amb Vlegels i Lievens (2017), analitza els processos de construcció social de categories artístiques i musicals a partir d'esquemes de classificació.

El que plantegem aquí és la necessitat de realitzar un canvi paradigmàtic que no busqui definir la creativitat en termes substantius i atributius. La creativitat no és una propietat associada a grups socials de forma rígida, sinó un mecanisme relacional, com promulga ja Bourdieu a nivell d'espai social i com recull la tradició anglosaxona que és la base dels estudis sobre cultura popular (Popular Culture). En efecte, el materialisme cultural de Raymond Williams i el gir cultural de Stuart Hall han posat en relleu la noció de la cultura popular com a base per a un altre tipus de legitimitats. Es tracta de qüestionar la jerarquia de legitimitats: El sociòleg britànic Simon Frith (1986), que en els inicis va estar molt lligat a l'escola dels Estudis Culturals de Stuart Hall, va descobrir el rol central de les escoles d'art britàniques en la consolidació de les carreres artístiques de músics com Bowie o artistes plàstics com Hockney, i per tant, va il-luminar la correspondència existent entre les pràctiques artístiques considerades el cim de la creativitat, amb els factors de classe i capital cultural de l'alumnat d'aquestes escoles.

\section{LA MICROSOCIOLOGIA DEL JUDICI CREATIU}

Marcel Duchamp, fundador de l'art contemporani el 1917 amb el seu ready made de l'urinari, va encunyar el 1957 la frase «L'art és una manera de mirar». Duchamp ja definia l'experiència artística i creativa com una forma de relació, sense entrar en el contingut substancial del que es considera una obra legítima en un lloc i moment determinats. Els estudis culturals han estat interessats durant dècades en el significat de les pràctiques al voltant de l'escolta amb tecnologies (Du Gay, 1997; Frith, 1986). Becker (2002) reivindica la necessitat de recuperar i d'innovar en la recerca de noves realitats culturals i artístiques que sorgeixen de l'àmplia distribució de les eines digitals i tecnologies afins. Alhora, la tecnologia pot analitzar-se en termes 
d'articulació de gènere segons eixos de classe, raça o etnicitat (Armstrong, 2011).

Cifariello (2017) analitza la creativitat en la distribució de formes musicals intervingudes per la tecnologia com un objecte d'estudi en si mateix. En definitiva, es tracta de seguir allò que ja apareix en Marx i que reprèn Rosenblum (Moulin, 1999: 174): «Tots els processos econòmics i socials de postproducció afecten la producció en forma de retroalimentació recíproca, com a part d'un sistema total de producció/ distribució». D’una banda, el procés artístic depèn de les relacions d'intercanvi, distribució i consum del mercat; i d'altra banda, els artistes necessiten controlar el procés d'intercanvi que implica entrar en el mercat de l'art. Les anàlisis micro de la vida quotidiana (DeNora, 2014) i les comparacions internacionals de categories conceptuals i de classificació (Fourcade, 2012) busquen comprendre de forma pragmàtica les categories socials de criteri i gust com a processos de categorització i d'avaluació. Aquesta experiència és complexa $i$, sobretot, col-lectiva. Moschetta i Vieira (2018) van entrevistar usuaris de la plataforma de streaming Spotify per analitzar les seves noves pràctiques de descobriment i consum musical. Afirmen que, si bé els usuaris utilitzen els algoritmes del programa per escoltar recomanacions en línia, el seu primer criteri de referència són els consells i les recomanacions personals de familiars $i$ amics, de manera que la construcció del gust musical segueix sent purament social.

A més, en l'última dècada s'ha establert una relació directa entre cos i música (Muntanyola-Saura, 2014; 2016). Una frase de dansa sorgeix de la multitud de micro-decisions creatives i comunicatives de qui participa a l'assaig, tant de les ballarines com del coreògraf. Sennett (2012), més fenomenològic, en parlar de la creativitat dels luthiers, fa una descripció detallada de la seva feina al taller com a artesans de la fusta, explicant el seu procés de treball com una successió de gestos informals, hàbits formals i gestos incorporats. Cita explícitament el paradigma de la cognició corpòria (embodied cognition) de Dreyfus (1996), Clark (2008) i Gibbs (2006). Diu: «Intentaré mostrar com el treball manual pot instigar un comportament social dialògic» (Sennett, 2012: 199). Explicar com els cossos interactuen i determinar la proximitat entre la ment i el seu embolcall biològic són principis rectors de la recerca actual en processos cognitius.

Per comprendre la construcció de la creativitat hem d'entrar, doncs, en la dinàmica d'interacció i comunicació a la base de la creació de categories i judicis experts (Teil, 2004; Hennion, 2005; Lena i Peterson, 2008; Fourcade, 2012). Introduïm el terme «expert» desvinculat de la seua connotació social elitista i individualista des del materialisme cultural: expert és aquell que juga i parla amb els termes acumulats i transmesos dins d'un espai social determinat, com pot ser l'escena musical (DelVal, 2017). Ens allunyem també de l'essencialisme en considerar que les pràctiques i discursos experts no són fixos, sinó que canvien i es transformen segons el temps i el lloc.

Aquesta forma d'analitzar les pràctiques creatives, contextualitzades i objectivades, forma part de la tradició de l'etnometodologia, que porta des dels 80 analitzant processos d'interacció en entorns institucionals diversos, com hospitals, restaurants, museus, aules o comissaries (Cicourel, 2002; Lieberman, 2013; DeNora, 2014; Fele, 2016; Mas, 2017). El punt de partida de l'etnometodologia és considerar que els processos de judici, avaluació i categorització no són expressions més o menys espontànies de preferències individuals. Aquests judicis es donen en un entorn institucional i en un marc geogràfic concret. No hi ha res més real que el que la gent ha acordat; el que és central (en la perspectiva pragmàtica) és la definició de la situació. Tot procés de coneixement i de comunicació segueix unes regles d'interacció que podem observar i analitzar i que sorgeixen també del mateix context. Les percepcions individuals sobre l'objecte cultural es comparteixen, es presenten a l'altre, i es van ajustant en un procés de reciprocitat que pot anar cap al consens o cap al dissens. En tots dos casos, els judicis finals són productes intersubjectius sobre la pròpia experiència subjectiva. 
Els perfumistes bloguers de l'article d'Alac (2017) desenvolupen un llenguatge públic i ho fan filtrant i compartint la seva experiència individual. Els bloguers prenen la inefabilitat de l'olfacte com un desafiament, per comprometre's amb els altres en un acte de creativitat col-lectiva. El millor del gust o del judici estètic és que transcendeix la subjectivitat en compartir públicament experiències individuals dins d'un vocabulari específic que legitima el que es diu. La tardor passada vaig assistir a la Biennal d'Art de Venècia. El cèlebre pavelló italià de l'artista Cuoghi presentava figures religioses amb florit en diferents nivells de descomposició. L'olor d'espores florides juntament amb els diferents nivells de temperatura i l'efecte visual de la descomposició va desembocar en una experiència intensa que captiva un públic format per aficionats i professionals que parlaven i prenien fotografies. Es feien comentaris compartits sobre experiències individuals que es filtraven en el lloc.

El diàleg és selectiu. És a dir, quan parlem d'art o de menjar no compartim totes les propietats constitutives del que estem contemplant o gaudint (Fele, 2016). Quan estem en un concert no relatem cadascuna de les nostres sensacions, pensaments i avaluacions al nostre company que està dret al nostre costat, sinó que fem uns quants comentaris espontanis que filtren la nostra experiència. I el resultat final, el nostre parer, és el resultat d'aquests comentaris validats i comunicats socialment $\mathrm{i}$ que poden prendre la forma de, per exemple, fotografies compartides en xarxes socials. De fet, la major part del temps, la conversa a la feina és multimodal. En el meu treball sobre la dansa (Muntanyola-Saura, 2014) els ballarins fan servir el terme lingüístic «escoltar» per descriure el seu propi treball en xarxa en duets i trios. Es refereixen a una postura comunicativa més enllà de la parla que inclou la mirada, els gestos, l'espai i el ritme.

Seguim els nostres propis sistemes de rellevància (Schütz, 1972), producte del procés de socialització, fet per experiències passades familiars i amicals. Però al mateix temps, l'actualitat de l'intercanvi, la disponibilitat de l'altre per escoltar i la seqüència de la conversa conformen el discurs. El judici creatiu passa en aquest moment, en la conversa, i no necessàriament preexisteix a nivell neuronal o individual. L'acte estètic és un acte d'atenció compartit, com afirma Hennion (2005) quan parla de tast de vins i inclou moments d'inspiració i emoció musical (Green, 2016).

L'objecte etnometodològic, en definitiva, apareix en el moment en què pronunciem un judici de valor sobre la nostra experiència creativa que, tal com Hennion (2005) posa de manifest, gira entorn de l'acte de parar atenció. Segons Lieberman (2013), els participants dels actes de degustació no estan només interessats en descriure el sabor del cafè. El que volen és compartir experiències, categoritzar i avaluar per anar més enllà dels sabors que ja han identificat. Tenen ganes d'apreciar amb més detall aquell gust o matís concret, i aprendre què és, com reconèixer-ho i com descriure-ho. Aquest procés d'aprenentatge participatiu eleva el nivell d'expertesa. Hennion (2005) defensa que el gust no és una cosa que estigui determinada socialment, sinó que és una activitat, i que el grau de creativitat que desprèn dependrà de molts factors: dels estats d'ànim, de les mediacions tecnològiques o dels espais on es consumeix música.

\section{CONCLUSIONS}

El fil conductor d'aquest article és la constatació que els judicis del gust $i$ les decisions creatives estan condicionades pel joc posicional dels consumidors associat al capital cultural, la classe social, el sexe o l'edat, entre d'altres. Aquests factors socials construeixen i legitimen, però també acomplexen i desmobilitzen, i també fomenten l'elitisme i el populisme. Socialment, la creativitat s'identifica amb processos cognitius que tenen lloc en contextos artístics i científics, o bé en judicis estètics i del gust que tenen lloc en la vida quotidiana. El gust és una forma de discriminació, la nostra capacitat d'analitzar, identificar, reconèixer i nomenar allò que percebem.

No podem ignorar la dinàmica de la distinció en la reproducció, en els termes de Bourdieu. Quan els per- 
fumistes aficionats que estudia Alac (2017) es burlen dels vocabularis professionals, s'estan distanciant d'un grup d'experts avantatjats en termes de recursos simbòlics i capital cultural. És un mecanisme de defensa contra l'estructura jeràrquica de la societat. En aquest sentit, hi ha una consciència creixent de la influència dels interessos comercials, del poder o de les jerarquies socials en els nostres judicis que porta a sospitar de qualsevol jerarquia de coneixement o pràctica cultural que aconsegueixi legitimar-se, així com al menyspreu i la desconfiança cap a la noció d'expert o especialista (Dreyfus, 1996). Els debats recents entorn del que s'ha anomenat «populisme polític» i «postveritat» són fruit d'aquestes dinàmiques.

La creativitat no passa en un buit sinó que té lloc en un context institucional específic. La institució a la qual pertanyem dona forma no només als temes del que diem, sinó també a com ho diem. El llenguatge es torna sagrat en termes d'un vocabulari respectat perquè està vinculat a un sistema social de rellevància (Schütz, 1972). L'experiència de la creativitat no és només interna, sinó que es fa necessàriament pública. Aquest kitkat fenomenològic resulta en un canvi d'actitud que es troba en l'arrel de la capacitat per formular de manera col-laborativa criteris d'apreciació cultural. Qualsevol procés social implica aprenentatge, que en sociologia de la cultura localitzem en els processos de socialització primària i secundària. L'aprenentatge implica etapes específiques, des de principiants fins a experts, que no són aleatòries i que requereixen diferents criteris de legitimitat cultural i d'atenció compartida. Els estudis que presentem aquí recullen processos intersubjectius de creació i transmissió de criteris més o menys legítims de consum cultural, categoritzacions, avaluacions i judicis estètics.

Sociològicament, necessitem saber més sobre els atributs de la pràctica considerada creativa: la posició dels seus productors en l'estructura social, des d'on parlen, quin ha estat el seu procés de socialització i com és la seva experiència professional. Existeixen precedents teòrics en la tradició etnometodològica, però també en els diversos enfocaments relacionals que hem anat comentant en les seccions anteriors. A més, una postura relacional real necessita incorporar canvis metodològics i paradigmàtics, i entrar en la comprensió de les pràctiques creatives en el seu context de producció. L'anàlisi etnogràfica de com parem atenció als objectes creatius no se centra en uns atributs específics, sinó en la dinàmica de la interacció i la conversa. Els criteris per avaluar i classificar el que és bo i el que és dolent, allò que té qualitat i allò que no, i en quins termes, ja no són el monopoli dels experts, com ho veiem en l'explosió de bloguers aficionats, escriptors, fotògrafs, divulgació científica i likes. Sembla que per evitar el màrqueting pur i l'amateurisme populista, es necessita més conversa. La perspectiva sociològica pot protegir de la manipulació si es reforcen les eines crítiques de la creativitat.

\section{REFERÈNCIES BIBLIOGRÀFIQUES}

Adorno, T. i Horkheimer, M. (1994). Dialéctica de la Ilustración. Fragmentos filosóficos. Madrid: Trotta.

Alac, M. (2017). We like to talk about smell: A worldly take on language, sensory experience, and the Internet. Semiotica, 215, 143-192.

Armstrong, V. (2011). Technology and the Gendering of Music Education. Farnham: Ashgate.

Ariño, A. i Llopis, R. (2017). Culturas en tránsito. Madrid: Fundación SGAE.

Becker, H. (1982). Art worlds. Berkeley: Berkeley University Press.

Becker, H. (2002). Studying the New Media. Qualitative Sociology, 25(3), 337-343.

Becker, H. (2017). Creativity is Not a Scarce Commodity. American Behavioral Scientist, 61(12), 1579-88.

Berger, P. i Luckmann, T. (1988). La construcció social de la realitat. Barcelona: Herder. 
Bourdieu, P. (1979). La distinction. París: Seuil.

Bourdieu, B. (1984). Raisons Practiques. París: Seuil.

Bourdieu, B. (1994). Les regles de l'art. París: Seuil.

Brekhus, W. H. (2015). Culture and Cognition. Patterns in the Social Construction of Reality. Cambridge: Polity Press. Bunge, M. (2018). Diccionari filosòfic. Barcelona: Institut d'Estudis Catalans (IEC).

Clark, A. (2008). Supersizing the mind. Oxford, UK: Oxford University Press.

Cicourel, A. (2002). The Interaction of Discourse, Cognition and Culture. Discourse Studies, 8(1), 25-29.

Cifariello, F. (2017). Creativitá musicale di consumo. En G. Fele, M. Russo i F. Cifariello (ed.), Creativitá musicali. Narrazioni, practiche e mercato. Milà: Mimesis.

Damasio, A. (1999). The Feeling of What Happens: Body and Emotion in the Making of Consciousness. Nova York: Harcourt Brace.

DelVal, F. (2017). Rockeros insurgentes, modernos complacientes: un análisis sociológico del rock en la Transición (19751985). Madrid: Fundación SGAE.

DeNora, T. (2014). Making Sense of Reality: Culture and Perception in Everyday Life. Londres: Sage.

Dennett, D. (1995). Darwin's dangerous idea. Nova York: Simon \& Schuster.

DiMaggio, P. (1987). Classification in Art. American Sociological Review, 52(4), 440-455.

Dreyfus, H. (1996). The current relevance of Merleau-Ponty's phenomenology of embodiment. The Electronic Journal of Analytic Philosophy, 4.

Du Gay, P. (1997). Doing Cultural Studies: The Story of the Sony Walkman. Londres: Sage/Open University Press.

Eagleton, T. (2000). The idea of culture. Londres: Blackwell Publishing.

Fele, G. (2016). Il paradosso del gusto. SocietàMutamentoPolitica, 7(14), 151-174.

Feyerabend. P. (1975) Against Method. Nova York: Verso Books.

Feyerabend, P. (1987). Creativity: A Dangerous Myth. Critical Inquiry, 13(4), 700-711.

Frith, S. (1986). Art versus technology: The strange case of popular music. Media, Culture \& Society, 8, $263-279$.

Fourcade, M. (2012). The Vile and the Noble: On the Relation between Natural and Social Classifications in the French Wine World. Sociological Quarterly, 53(4), 524-545.

Gallese, V., Keysers, C. i Rizzolatti, G. (2004). A unifying view of the basis of social cognition, Trends in Cognitive Science, 8, 396-403.

Gibbs, R. (2006). Embodiment and cognitive science. Nova York: Cambridge University Press.

Green, B. (2016). "I Always Remember That Moment": Peak Music Experiences as Epiphanies. Sociology, 50(2), $333-348$.

Heinich, N. (1999). La sociologie et les publics de l'art. En Moulin, R. (op.cit)

Hennion, A. (2005). Pragmatics of Taste. En M. Jacobs i N. Hanranhan, The Blackwell Companion to the Sociology of Culture (p. 131-144). Oxford: Blackwell.

Joas, H. (1996). The creativity of action. Chicago: University of Chicago Press.

Johnson, C., Dowd, T. i Ridgeway, C. (2006). Legitimacy as a Social Process. Annual Review of Sociology, $32,53-78$. Jacobi, D. i Luckerhoff, J. (2012). Looking for non-publics. Presses de l'Université du Québec.

Kirsh, D. (2009). Projection, Problem Space and Anchoring. En N. A. Taatgen i H. van Rijn (ed.), Proceedings of the 31st Annual Conference of the Cognitive Science Society (p. 2310-2315). Austin, TX: Cognitive Science Society.

Lamont, M. (2010). Looking back at Bourdieu. En E. B. Silva i A. Warde (ed.), Cultural analysis and Bourdieu's legacy: settling accounts and developing alternatives (p. 128-141). Londres: Routledge.

Latour, B. (1986). Visualisation and Cognition: Thinking with Eyes and Hands. Knowledge and Society Studies in the Sociology of Culture Past and Present, 6, 1-40.

Lena, J. C. i Peterson, R. A. (2008). Clasificación as Culture: Types and Trajectories of Music Génders. American Sociological Review, 73(5), 697-718.

Lieberman, K. (2013). More Studies in Ethnomethodology: studies of the in vivo organization of sense. State University of New York Press.

Lipovetsky, G. (2007). Le bonheur paradoxal. Essai sur la société d’hyperconsommatiom. París: Gallimard. 
Lipovetsky, G. i Serroy, J. (2015). La estetización del mundo. Barcelona: Anagrama.

Lizardo, O. (2004). "Mirror Neurons," Collective Objects and the Problem of Transmission: Reconsidering Stephen Turner's Critique of Practice Theory. Journal for the Theory of Social Behaviour, 37(3), 219-350.

Lizardo, O. (2004). The Cognitive Origins of Bourdieu's Habitus. Journal for the Theory of Social Behaviour, 34(4), 375-401.

Lizardo, O. i Strand, M. (2010). Skills, toolkits, contexts and institutions: Clarifying the relationship between different approaches to cognition in cultural sociology. Poetics, 38, 204-227.

López-Sintas, J.L., Cebollada, A., Filimon, N. i Gharhaman, A. (2014). Music access patterns: A social interpretation. Poetics, 46, 56-74.

Mas, X. (2017). La música clàssica contemporània: una perspectiva etnomusicològica. Tesi doctoral de sociologia, Universitat de València.

Merton, R. K. (1945). Sociological theory. American Journal of Sociology, 50(6), 462-73.

Moschetta, P. H. i Vieira, J. S. (2018). "Music consumption in the streaming era: Music curation practices in Spotify", Congreso KISMIF 2018: Gender Differences, Identities and DIY Cultures. Universidad de Porto, 2-3 Julio.

Moulin, R. (ed.) (1999). Sociologie de l'art. París: L'Harmattan.

Muntanyola-Saura, D. (2012). La decisió artística i les seves condicions de producció: parlant amb un equip de rodatge. Athenea Digital, 12(2), 89-109.

Muntanyola-Saura, D. (2014). How multimodality shapes creative choice in dance. Revista Española de Sociología, 72(3), 563-582.

Muntanyola-Saura, D. (2016). La musicalidad como parte de la cognición distribuida en danza. Methaodos. Revista de ciencias sociales, 4(1), 163-175.

Premack, D. (2004). Is Language the Key to Human Intelligence? Science, 303, 318-320.

Ramachandran, V. S. i Blackeslee, S. (1999). Phantoms in the Brain: Probing the Mysteries of the Human Mind. Nova York: William Morrow.

Regev, M. (2013). Pop-rock Music. Aesthetic Cosmopolitanism in Late Modernity. Cambridge UP.

Rendueles, C. (2013). Sociofobia. El cambio político en la era de la utopía digital. Madrid: Capitán Swing.

Rosenblum, B. (1999). Artists, Alienation and the Market in Moulin (op cit).

Searle, J. (2004). Mind. Oxford University Press.

Sennet, R. (2012). Together. Londres: Penguin Books.

Schütz, A. (1972). Collected Papers vol. I. Països Baixos: Springer.

Stuart Hall, E. (2007). Richard Hoggart, The Uses of Literacy and the cultural turn. International Journal of Cultural Studies, 10(1), 39-49.

Stuart Hall, E., i Jefferson, T. (ed.) (1998 [1975]). Resistance Through Rituals: Youth Subculturas in Post-war Britain. Londres, Nova York: Routledge.

Teil, G. (2004). De la coupe aux lèvres. Pratiques de la perception et mise en marche des vins de qualité. Tolosa: Éditions Octarès.

Vandenberg, T. et al. (2018). "Taste patterns of the 'illegitimate' cultural consumer", Congreso KISMIF 2018: Gender Differences, Identities and DIY Cultures. Universidad de Porto, 2-3 Julio.

Vlegels, J. i Lievens, T. (2017). Music classification, genres, and taste patterns: A ground-up network analysis on the clustering of artist preferences, Poetics, 60, 76-89.

Williams, R. (1992 [1958]). Culture and Society. Londres: The Hogarth Press.

\section{NOTA BIOGRÀFICA}

Dafne Muntanyola-Saura és professora agregada i vicedegana de la Facultat de Ciències Polítiques i de Sociologia de la Universitat Autònoma de Barcelona. Ha estat becària del Programa FPU i becària de Caja Madrid a la Université de Nice, Fulbright Scholar al Departament de Ciència Cognitiva de la University of California, San Diego (UCSD) i professora a la Universidad Autónoma de Madrid. Les seves investigacions interdisciplinàries aborden els processos 
d'interacció comunicativa en entorns artístics i quotidians. Posen atenció al gènere i a la cognició seguint una metodologia mixta, etnogràfica, audiovisual i d'anàlisi per xarxes socials. Ha publicat a múltiples revistes internacionals i ha participat als principals congressos en sociologia de les arts, de la cultura i de sociologia cognitiva. És aficionada a escriure ressenyes de llibres. 